\title{
Christopher Scholz
}

\section{Geldmarktsteuerung und Krisenprävention}

Die staatliche Leitung der Reichsbank nach dem Bankgesetz vom 14. März 1875

[Money Market Regulation and Preventing Economic Crisis. Controlling the Reichsbank with 1875's Banking Act.]

Published in German.

The Reichsbank was set up in 1875 as the German Empire's first state-controlled bank with private shareholders. Christopher

CHRISTOPHER SCHOLZ

Geldmarktsteuerung und Krisenprävention
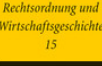

Mohr Siebeck

2016. XVI, 311 pages. ROWG 15

ISBN 978-3-16-154207-7

sewn paper $79,00 €$

ISBN 978-3-16-160620-5

eBook PDF $79,00 €$
Scholz examines the legal historical reasons for this within a European context.

Christopher Scholz Geboren 1984; Studium der Rechtswissenschaft in Bonn; Wissenschaftlicher Mitarbeiter bei einer Rechtsanwaltskanzlei; Wissenschaftlicher Mitarbeiter am Rheinischen Institut für Notarrecht der Universität Bonn; seit 2015 Rechtsreferendar am Landgericht Bonn.
Order now:

https://www.mohrsiebeck.com/en/book/geldmarktsteuerung-und-krisenpraevention-9783161542077?no_cache=1 order@mohrsiebeck.com

Phone: +49 (0)7071-923-17

Fax: +49 (0)7071-51104 